\title{
Critical discourse analysis in patriarchal society: Covid-19 and increased women workload
}

\author{
Khirjan Nahdi ${ }^{1}$, Muh. Taufiq ${ }^{1}$, Dukha Yunitasari ${ }^{1}$, Samsul Lutfi ${ }^{1}$, Suhartiwi Suhartiwi ${ }^{1}$, Usuludin \\ Usuludin $^{1}$, Roni Amrulloh ${ }^{1}$ \\ ${ }^{1}$ Universitas Hamzanwadi, Indonesia
}

\begin{tabular}{l}
\hline \hline Article Info \\
\hline Article history: \\
Received Jan $09^{\text {th }}, 2021$ \\
Revised Feb $02^{\text {nd }}, 2021$ \\
Accepted Mar $04^{\text {th }}, 2021$ \\
\hline
\end{tabular}

\section{Keyword:}

Critical discourse

Patriarchy

Women's workload

Covid-19

\begin{abstract}
By utilizing discursive theory, social actors, and sociosemantics, this study aims to find the increase in women's working hours, reasons, and causality between working hours, types of work, and their respective recognition in social relations. The study used a qualitative descriptive method, with research data focusing on the context before and during COVID-19. Data were collected through online surveys and interviews. Data analysis was carried out based on sociosemantic analysis in Critical Discourse Analysis (CDA), starting with calculating working time, reasons, and causality according to the CDA. The research findings show that women's working hours when COVID-19 has increased accumulatively. The accumulative increase relates to all types of work when COVID-19 requires women's access. Respondents admitted that everything was done as a custom for reasons of fate, obligations and traditions. It can be concluded that, there is a causality between working hours, type of work and respondents' reasons that prevalence occurs due to cognitive involvement, religion, and tradition. CDA views the context of this imbalance in this relationship as a social problem. Problem solving according to the CDA can be done through an educational process, with the assumption of solving problems for the future.
\end{abstract}

(C) 2021The Authors. Published by IICET.

This is an open access article under the CC BY-NC-SA license

(https://creativecommons.org/licenses/by-nc-sa/4.0

\section{Corresponding Author:}

Khirjan Nahdi,

Universitas Hamzanwadi

Email: khirjan.nw@gmail.com

\section{Introduction}

Asia and The Pasific SDG Progress Report (2020) report that the global development agenda shows a positive trend. Hopefully the no one left behind the principle will come true in 2030. It is not expected that in December 2019 the Corona virus (COVID-19) will hit the world, including Indonesia. Basri (2020) estimates, COVID-19 impact's liquidity, productivity and consumption. World Food Programme (2020) ) reports that since March 2020 prices of basic necessities have tended to rise to $60 \%$ in traditional markets in Java, and $33 \%$ outside Java. Although there are no official data on positive effects, social distancing and physical distancing policies are expected to reduce the spread of COVID-19. However, social distancing and physical distancing policies are not without problems. Stay at home (SAH) and work from home (WFH) has an impact on increasing women's work time in the household in the patriarchal community in Indonesia. The average work time for women is 35 to 40 hours / week, as ILO policy reported Dejardin (2011) could double. Alisyahbana, et.al (2017) said that this condition was a separate issue in the effort to create a parallel context between men and women in Indonesia, as targeted through Indonesian SDGs. Contextual reality shows the opposite 
condition, that men are still in a dominant position, especially in public access. This study is important in uncovering the fact that the context of COVID-19 with the Stay at Home and Work From Home policies increases the workload of women as a result of the context of a patriarchal society.

Patriarchal culture as a legacy of past civilizations has become a global humanitarian issue in developing countries in Asia and Africa, including Indonesia. Nahdi, Usuludin, Wijaya, \& Taufik, (2019) sees this problem as a social problem, in which there is an interest of actors in perpetuating the dominance of their relations. As a social problem, like Fairclough and Wodak, this condition is a social discourse that must be parsed and provide solutions, with the hope of reducing the prolonged negative impact on women. UNICEF (2020) released five women's protection agendas in the context of COVID-19; protection of women, reducing violence, health and education services, ensuring the availability of health information, and providing valid and methodological data for taking strategic steps.

This study is in response to the existing conditions of achieving SDGs in Asia Pacific, policies addressing COVID-19, the adverse impact of patriarchal culture on women, especially during the COVID-19 period. Referring to Fairclough Critical Discourse Analysis (CDA); Wodak \& Meyer, this study aims to find the level of the increase in women's work hours in households in patriarchal societies related to COVID-19 policies; find the arguments of patriarchal society, and recommend a strategic agenda of its adverse effects on women. Gender equality agenda by several parties on the surface. Historical and cultural reasons are not yet complete, so gender discrimination continues. The education sector must be given greater responsibility to unravel this problem, because today's generation is the future generation of 2030-2045 to come.

Bressler (2007) mentions patriarchy as a social system that positions men as the main figure in social organizations. The patriarchal society views women as weak and helpless. Nash \& Catharines (2020) explains, patriarchy is a system of relations between men and women who are believed, political values, economic, and social structures that have an impact on the misalignment of male and female positions. Jackson (1992) mentions that patriarchal culture is a long history of sociology and is heavily influenced by capitalism. The tendency of capitalism because of patriarchy encourages the mastery of sources of capital by men. The condition referred to as Jackson makes women seem without choice. Rollefson (2017) gives an example to the Rajasthan community, which is very dependent on men or husband. Another example occurs in Bangladesh, as described Naved, Rahman, Willan, Jewkes, \& Gibbs (2018), patriarchal society is related to the need for violence, domination and control of men against women.

The dynamics of patriarchal culture show a different tendency. Turkey as one of the countries with a majority of Islam has experience in internalizing patriarchy through families with consideration of biological conditions, and basic rights of women. Dildar (2015); Demirhan, et.al (2015) shows respect for the dignity of women as well as the alignment of all humanity in Islamic teachings. Women are given space and time to maintain reproductive health during the childbearing age. Women have the same right to obtain proper education and not to work and marry at an early age. Other conditions occur in Arab society. Without mentioning patriarchal culture, Friedman-sokuler \& Justman (2019) clearly shows the discrimination of choice of science in higher education between men and women. Male students are predominantly directed at mathematics, science, and computers, while women are directed towards social, humanities, and literature choices. The reason, men will continue the development process in strategic areas outside the household context. Shahriar (2018) women in patriarchal societies have a low tendency to pursue the world of entrepreneurship. Different cases in matrilineal society, women have a high tendency to pursue entrepreneurship. This difference is not without reason, that in a patriarchal society, women will be the dominant male or husband. In matrilineal society, women will determine the future direction of the family, because men live in women's family homes. Salviana \& Soedarwo (2014) show the influence of Javanese patriarchal culture on political opportunities for women. Political participation of women is more limited than men for culinary reasons. Both of these realities can be explained that women's tendency to choose public agendas is determined by the availability of space and time. The wide availability of space and time allows women to appear in the public domain as well as men. In addition to the creation of space and time, internalization with various reasoning is very strategic in creating equality between men and women.

As Fairclough said, CDA allows the search for language or text relations, power, and ideology in social interactions. Social interaction between men and women is a text. Nayak (2017) imbalance of relations between men and women in a patriarchal society is a text that is full of meaning, can be explained through discursive reasoning that is constructed through the creation of texts. Haryatmoko (2010) said that relations between men and women who tend to be discriminate are violent practices. Violence in this context is intended as an act that forces the other party without consent, which results in psychological damage, ways of thinking and behaving. According to Fairclough, there is a dialectical relationship between the reality of action in a text with the intention of action against other groups in their social relations. In the historical context, 
Wodak and Meyer explained, social practices that tend to deny the existence of women are inseparable from the desire to preserve the history of patriarchal society. This social practice is considered a legacy from the past that benefits them. In such social relations, actors in the context of patriarchy are men as van Leeuwen mentioned.

Huckin, Andrus, \& Clary-Lemon (2012); Rezanova \& Kogut (2015); Boldyrev \& Dubrovskaya (2016) refer to this kind of practice as an attractive relation of texts and socio-cultural contexts that were intentionally created. Men and women are positioned differently in social structures. Hiller \& Baudin (2016) show that cultural aspects play a role in forming different patterns of relationship through different educational choices between boys and girls. Two key words from the view of Fairclaugh, Wodak and Meyer, and van Leeuwen namely dialectics and historical heritage. The reality of increasing women's work time in the context of COVID-19 is dialectical reality in the form of male power over women in social relations. Social relations in the context of this study are in the household. Because Indonesian society is a patriarchal society, this practice is a legacy of the past that is perpetuated in the current modern era. Moreno (2010) points out discrimination against women in bureaucratic structures in Spain. Likewise, the dual role of women in Portugal in Santos (2015). Schnurr, Zayts, Schroeder, \& Coyte-hopkins (2019); Seymour (2009), shows a gender bias in the relations of men and women in modern society. The evidence shows the failure of the equality agenda for men and women. Skinner (1987) in his studies of patriarchy and feminism has shown tendencies in men for various reasons. It is no exaggeration if Orgad (2019) mentions, "equality is only hoped." This reality is discursive, understood as a social problem.

As a social problem, this condition can be decomposed and radiated. Liu (2012) found migration trends as an alternative to finding a balance between men and women. This case does not solve the problem fundamentally because not all families choose migration. Said-allsopp \& Tallontire (2014) offers an alternative to Global Value Chains (GVCs) as an alternative to eliminating the impact of patriarchy. Swart, California, \& Angeles (2015); Frias (2010); Dyson (2019); Bleck \& Michelitch (2018); dan Rincón \& Martínez (2020), each calling patriarchy a global phenomenon. Because it needs the power of the state, political power, and society in changing the mindset of society about patriarchy and its various unfortunate consequences. The process of strategic education in building new concepts about equality of men and women.

\section{Method}

This type of study is a qualitative descriptive study. The study data was collected through a survey of 416 respondents throughout Indonesia online and offline. The study instrument used a direct survey questionnaire (offline) and google form (online). The data were analyzed in the following stages: 1) calculate the comparison of women's working hours in the household before and during COVID-19; 2) grouping the views of women and men in the context of work hour's comparison; and 3) discovering the causality of working hour reality according to the CDA based on the main principles of Fairclough dialectics, the historical aspects of Wodak and Meyer, and the sociosemantic role of van Leeuwen's actors. Therefore, the research questions to be answered through this study are related to: 1) What is the average number of hours worked by the household before and when COVID19? 2) What are the views of each in the gender relations of men and women in the family? 3) What is the causality shown by the answer to question number of 2 according to the aspect of CDA? This technique is in line with that done by Amer (2017). Amer only analyzes the text directly, while this study of social reality as a text, which is shown through social action (working hours), is completed with the text of the interview results.

\section{Result and Discussion}

Age, Age of Marriage, and Number of Families

The analysis begins with the respondent's general information. Figure 1 shows, the age of the respondents is classified as young and middle-aged. Respondents aged $20-30$ years (11.50\%); age 31-40 years (38.50\%); age $41-50$ years $(29.80 \%)$; and age $\geq 50$ years $(20.20 \%)$. The age of the respondents when the survey was conducted was relatively young and middle-aged 


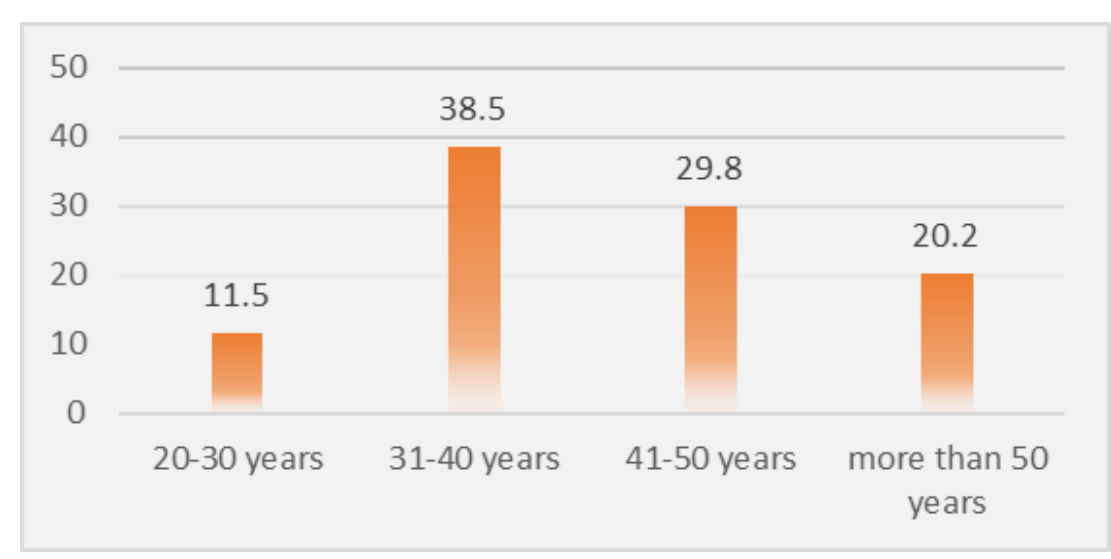

Figure 1. Age of Respondents

Data on age with the highest average is associated with the most average data on the age of marriage. It is estimated that the average age of marriage of respondents is under the age of 20 years. This age has only completed secondary school education, even in elementary school. This information is important as a cognitive reference in decision making in the household and family.

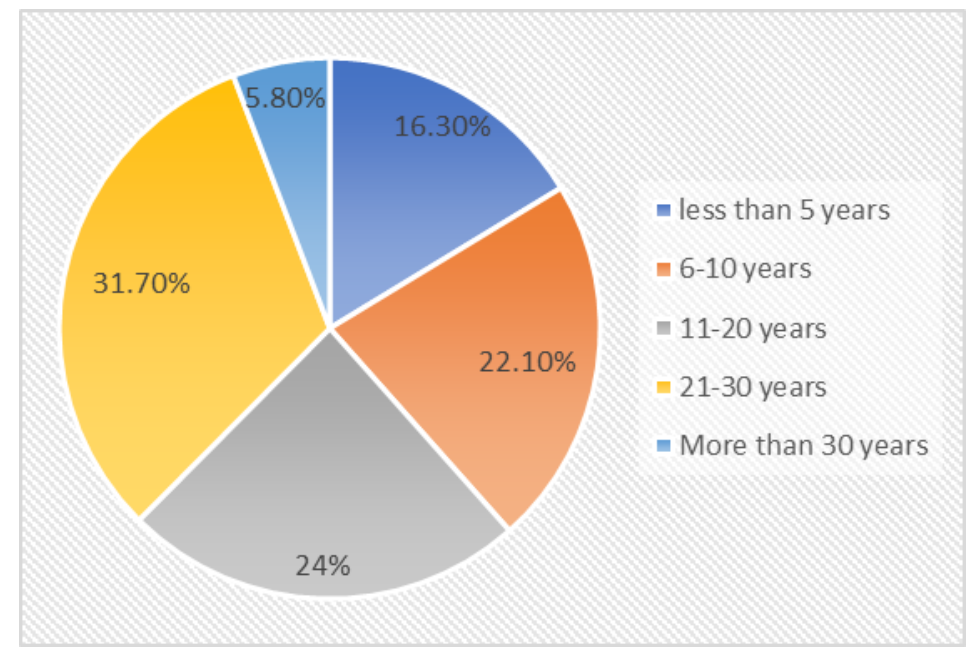

Figure 2. Age of Marriage

Figure 2, respondent's marriage age $\leq 5$ years (16.30\%); 6-10 years (22.10\%); $11-20$ years $(24.00 \%) ; 21-30$ years (31.70\%); and $\geq 30$ years (5.80\%). Figure 2 data show that the average age at marriage is $21-30$ years. With a marriage age of 11-20 years, the level of cognitive maturity when married is still at the level of high school graduates, even basic education. This condition is important to know that patriarchal societies often make the context of education an instrument supporting the justification of women's domination and domestication.

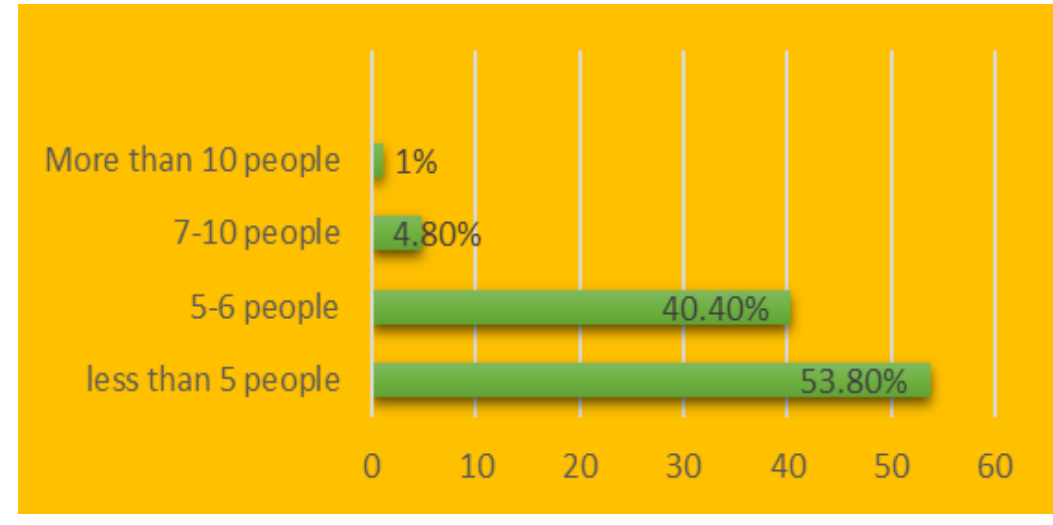

Figure 3. Number of families 
Figure 3 , number of families, $\leq 5$ people $(53.80 \%) ; 5-6$ people $(40.40 \%) ; 7-8$ people $(4.80 \%) ;$ and $\geq 10$ people (1.00\%). Information about the age of the respondent, age of marriage, and the number of important families is known to be related to the average number of hours worked multiplied by the number of families in all ages of marriage. In terms of age, respondents are classified as young and middle-aged. Physically, young and middle-aged have enough energy to do various activities. Simulation: age 40 years, marriage age 10 years, with a family of six people, with household time before COVID19 $=6$ hours $/$ day, equivalent to 42 hours / week. If it is assumed, these six families since the last five years, means the respondent has invested 10,080 hours of work time in domestic work. This amount increased during COVID-19 became an average of seven hours, so since the last five years it has invested 11,760 work hours of domestic work. What's interesting about this simulation, the data shows the number of working hours $\leq 5$ hours / day decreases, but there is an increase in working hours to six hours? This condition means, with the gathering of all families at home, the respondent's household work increases on average 1-2 hours / day or 7-14 hours a week.

CDA views the condition as a problem, in which there is a discursive form of control or control by the actors, namely men. Control by actors is done to maintain the status of a family leader, with various domestic facilities (regulating, governing). This act of control and control is not an independent condition that suddenly occurs. This context is a reality of patriarchal society as a historical legacy which is accepted as fairness. As a historical legacy, this condition will continue in the next phase of history if it is not mediated. This mediation process can occur if each party views this relationship as a problem. At the local and cultural level, the mediation reference can be sourced from religious and human reasoning. Every religion teaches justice, including justice in the distribution of domestic and public work. Humanitarian reasoning, on the other hand, teaches that there is a balance between rights and obligations between men and women in all forms of social relations.

\section{Domestic / Household Work Time Information}

Women's domestic work in the phases before and during COVID-19 was distributed as shown in table 1.

Table 1. Distribution of Women's Work in the Household

\begin{tabular}{ccc}
\hline House chores & Before Covid-19 & During COVID-19 \\
\hline Assisted by a household assistant & $9,60 \%$ & $6,70 \%$ \\
\hline Assisted by husband & $44,20 \%$ & $53,80 \%$ \\
\hline Assisted by a child & $15,40 \%$ & $17,30 \%$ \\
\hline Do it by yourself & $30,80 \%$ & $22,10 \%$ \\
\hline
\end{tabular}

Table 1 shows: before COVID-19: 9.60\% of work assisted by household assistants; $44.20 \%$ assisted by husband; $14.40 \%$ assisted by children; and 30.80\% are done alone. During COVID-19, 6.70\% of the work was assisted by household assistants; $53.80 \%$ assisted by husband; $17.30 \%$ assisted by children; and $22.10 \%$ worked alone. The interesting things about this work distribution are: 1) there was a reduction in working hours assisted by household assistants and self-employed in the phase during COVID-19 compared to before. 2) there was an increase in work assisted by husband and children. This condition can be explained, when the COVID-19 phase, all family members are at home, which allows all domestic activities to take place at home. Indeed, COVID-19 phase work is assisted more by husband and children, but still women are the front guard in all matters of work. This condition can be confronted with the data in table 3 that the type of work that becomes the realm of women is still concentrated on taking care of eating and drinking (increased from $39.40 \%$ to $50.00 \%$ ), and caring for children (increased from $15.40 \%$ to $16,30 \%$ ).

There are problems in the relations of men and women in the context of the distribution of this work. The patriarchal society still considers kitchen work for food and drink, caring for children, and maintaining the home environment to be the realm of women. Discursive which is formed through this reality is the creation of texts that the type of work is the property of women and men outside the work. Of course, this reality is not a domestic reality of the present but a historical legacy of the past, which is to be maintained in the future. Sociologically, texts that align women with these three types of work are ideological practices that deliberately exclude women from all three. That means, men are in an exclusive position and outside the three jobs. So, there is a specification of linguistic context, that the affairs of the kitchen, caring for children, and caring for the home are the treasures of women, not men. 
Table 2. Working hours before and during COVID-19

\begin{tabular}{ccc}
\hline Availability of work time & Before Covid-19 & During COVID-19 \\
\hline Less than 5 hours & $53,80 \%$ & $60,80 \%$ \\
\hline 6-7 hours & $32,70 \%$ & $27,90 \%$ \\
\hline 8-9 hours & $7,70 \%$ & $5,80 \%$ \\
\hline More than 9 hours & $5,80 \%$ & $5,50 \%$
\end{tabular}

Table 2. It informs: women's working hours before COVID-19: working hours $\leq 5$ hours $(53.80 \%) ; 6-7$ hours $(32.70 \%)$; $8-9$ hours $(7.70 \%)$; and $\geq 9$ hours $(5.80 \%)$. Women's working hours during COVID-19: $\leq 5$ hours (60.80\%); 6-7 hours (27.90\%); $8-9$ hours (5.80\%); and $\geq 9$ hours (5.5\%). Data on women's working hours before and during COVID-19 can be understood that there is a reduction in work on the job by 6-9 working hours, but there was an increase in work $\leq 5$ hours. This condition means, still the involvement of women in all types of jobs that exist in the household. Reduction in the number of hours worked 6-9 hours because the whole family is at home in the COVID-19 phase. The problem is not with a reduction in working hours of 6-9 hours, but on an addition to work $\leq 5$ hours. That is, the type of work increases with the addition of members at home at the same time. The interesting thing is the involvement of women in all domestic work. From the average limited hours to work with an average of 8-9 hours, women are involved. This condition shows that women's access is always present in all types of domestic work.

Through CDA, it is understood that this condition contains social problems in relations between men and women in a patriarchal society. The reality of the relation between men and women contains discursive identification of identity that women are in line with domestic work, and men work outside it. Of course, this condition is a historical condition which is to be maintained by attaching the label of domestic work to women. Sociologically, men are in an inclusive context, and women are in an inclusive context with domestic work. Conditions are understood through context specifications, that all who deal with domestic work become the realm of women, and vice versa into the realm of men. The argument is clear, the patriarchal society will say that the condition has happened for generations, and so far there has been no problem. In fact, that reality is a problem according to religious and human reason, because it denies the aspects of justice and equality of rights and obligations.

Table 3. Types of Women's Work in the household

\begin{tabular}{ccc}
\hline Type of work & Before Covid-19 & During COVID-19 \\
\hline Take care of eating and drinking & $39,40 \%$ & $50,00 \%$ \\
\hline Take care and care for children & $15,40 \%$ & $16,30 \%$ \\
\hline Caring for her own clothes, children's clothes, and husband's clothes & $12,30 \%$ & $11,50 \%$ \\
\hline Caring for the home environment & $26,00 \%$ & $10,60 \%$ \\
\hline Another job & $6,90 \%$ & $11,60 \%$ \\
\hline
\end{tabular}

Table 3. It informs: before COVID-19, types of women's work in the household: eating and drinking (39.40\%); caring for the home environment (26.00\%); take care and care for children (15.40\%); take care of husband's clothes, children, and their own clothes (12.30\%); and other works (6.90\%). During COVID-19, the type of work of women in the household: eating and drinking $(50.00 \%)$; caring for the home environment $(10.60 \%)$; take care of and care for children (16.30\%); take care of husband's clothes, children and own clothes $(11.50 \%)$; and other works (11.60\%). As explained earlier, the discursively formed through social reality as well as the type of women's work in patriarchal household households is the creation of inclusivism and exclusivism of work. Type of work: preparing food and drink, caring for and caring for children, caring for the home environment, and taking care of the husband's clothes, children, and clothes themselves become inclusive work for women, as well as exclusive for men. The interesting thing is, in the four types of work, there was an increase in the number of respondents who were preoccupied with taking care of eating and drinking. An increase from $39.40 \%$ to $50.00 \%$. This condition is likely due to women working, so food and drink are prepared by assistants or husbands and children foraging for themselves. During COVID-19, all family members gathered at home, so that all food and drink needs become women's business.

CDA understands this condition as a problem. There is an imbalance through the creation of work parallels between men and women. The intent contained in this action is the perpetuation of the culture of domestication of women by men, as practiced by the patriarchal societies before. This context is a specific context within each patriarchal household, with the same value, which is to equalize women in domestic 
work. Semantically understood as the process of perpetuating domestication of women. As an amplifier of this analysis data, it can be confronted with the information of respondents' responses to the number of hours worked in the household that is their workload, in figure 4 and box 1 below.

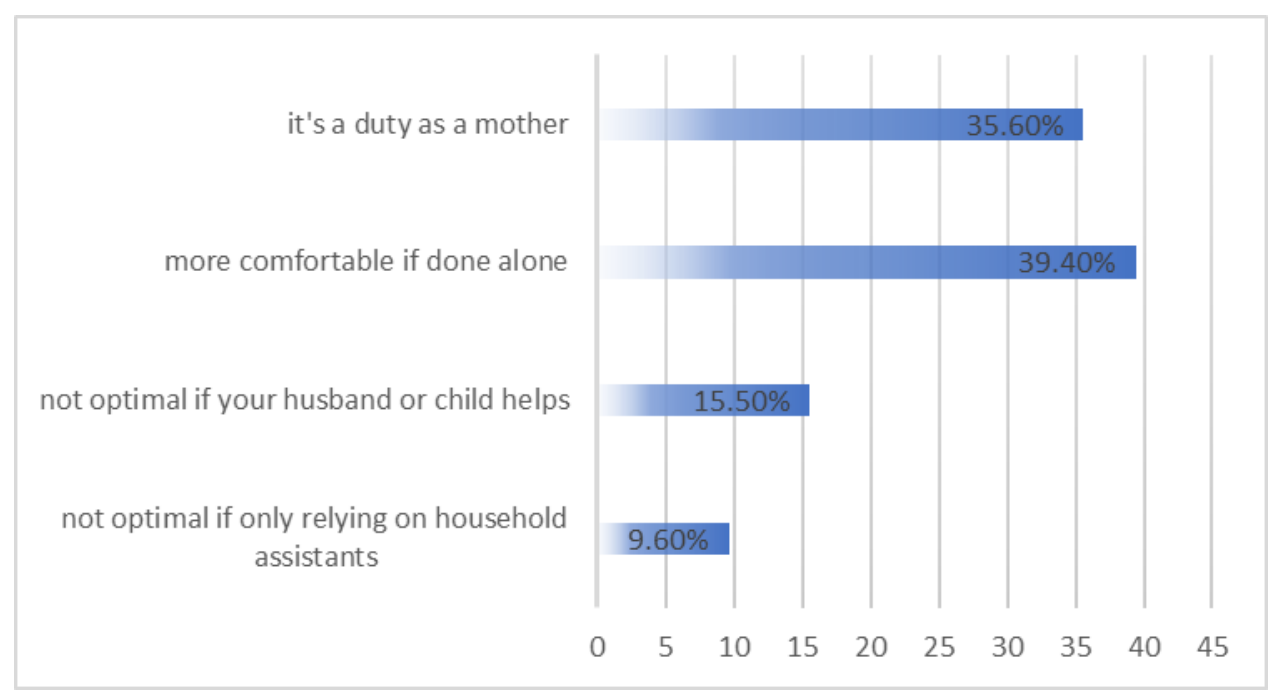

Figure 4. Distribution of Domestic Work Responsibilities

\section{Box 1. Respondents' responses}

1) I don't know, maybe it's the fate of a mother. Calculate for the assignments too, the father earns a living, and the mother does homework, if the mother earns a living and the father does the homework like a wife earning her husband. Not beautiful apparently ...

2) Actually household chores including dropping off and picking up my schoolchildren are always assisted by my husband, we always help each other. But if indeed all the work is my responsibility as a mother, then I will try to run it as well as possible.

3) Because the husband has quite a lot of busyness so housework I think the wife is doing

4) Fitrah as a housewife must also be done without a housemaid

5) Because my children are all boys

6) Because it is my responsibility as a wife and housewife

7) Mother's work does take care of the house and family

8) Because of the obligation to be a wife, domestic work is my responsibility and if I am a child laborer and my husband is ready to help with the work.

9) Because of the obligation of the wife to take care of the household

10) Our culture and duties as a mother should be accordingly according to the choice of answers (d)

11) Environment, hygiene and household matters are indeed shared obligations of family members

12) It's become a tradition

13) Feeling very maximal if the work is done even though it is a little, and although it is assisted by a husband

14) Apart from the obligation, there is also no cost to pay for $A R T$

15) All family members have their own basic obligations, for example, children basic learning / school obligations. Husbands earn a living. Wives take care of the household. But as a family still must help each other.

16) There is no problem because a mother is responsible for a household that is mandated by her husband, therefore, a mother must carry out the obligations sincerely, full responsibility according to ability, one thing that must be remembered that the husband's pleasure makes it easy for a mother / wife to get pleasure God

17) It is indeed the duty of a wife to do household chores

18) Clean the household

19) Housework is never finished from getting up in the morning, afternoon, even in the evening, but as a housewife, all of this work is done happily, sincerely and sincerely.

20) Because this is the habit of housewives

21) Because domestic work is a routine as a housewife with the help of her husband and child on the head of the family and family members by helping each other

22) Work is done alone

23) Because homework is my habit to do

24) Before or during COVID-19, most of the housework was always done by the mother

25) Actually, it's really tiring because besides taking care of the household I also have to work, but what else can I do, my duty as a mother (wife) 
26) Mother is everything's

27) Inevitably, it has the obligation as a mother

28) Sincerely work for the family

29) Because the wife's job is to serve prepare prepare all the household needs ranging from cooking, cleaning the preparing preparing clothes, etc. And because our house is small for what needs a household assistant.

30) Working husbands of children are more emphasized in learning activities

31) My husband is busy making a living, provision lockdowns

32) I am single parent

33) Because Islam teaches that a wife is obliged to serve and accompany her husband

Through Figure 4 and box 1, two information is obtained: information on the respondent's response to hours worked and the type of work before and during COVID-19, and comments from the interviews. Respondents' responses to the distribution of time and types of women's work in the household: not optimal if all is submitted to the household assistant (9.60\%); not optimal if assisted by husband and children (15.40\%); more comfortable to do alone (39.40\%); and indeed has the authority as a wife and mother (35.60\%). Based on the data in Figure 4, the four respondents' statements show that domestic work is inclusiveness for women and is exclusive to men. Respondents feel the maximum if all household work is done alone, and is considered an obligation. There are parallels between the respondents' answers on the questionnaire and the interview (data box 1), namely that domestic work is the dominant responsibility of the wife or mother, because it is considered destiny (see a statement number: 1, 4, 28, 29, and 33). Domestic work is considered an obligation (see a statement number: 6,7,8,9,14,1 and 25). Domestic work in a culture / tradition (see a statement number: 10, 12, and 20). Domestic work is done by the wife or mother because the children are all boys (see a statement number: 5). Domestic work is done by the wife or husband because there is a division of labor (see a statement number: 15,30 , and 31 ).

Data picture 4 and box 1 strengthen the understanding of the reality of relations between women and men in patriarchal society households according to the CDA, that the discursive built is the inclusiveness of domestic work into the treasures of women, is considered an obligation and historical tradition that must be maintained. Sociologically, the statement that domestic work is destiny, obligation, culture / tradition, because boys, and the division of labor are a choice of diction that perpetuates male domination of women in patriarchal society. Proof that the diction maintains male dominance because the confession was conveyed by themselves (respondents), without any pressure from the men. So, this reality is considered as normal.

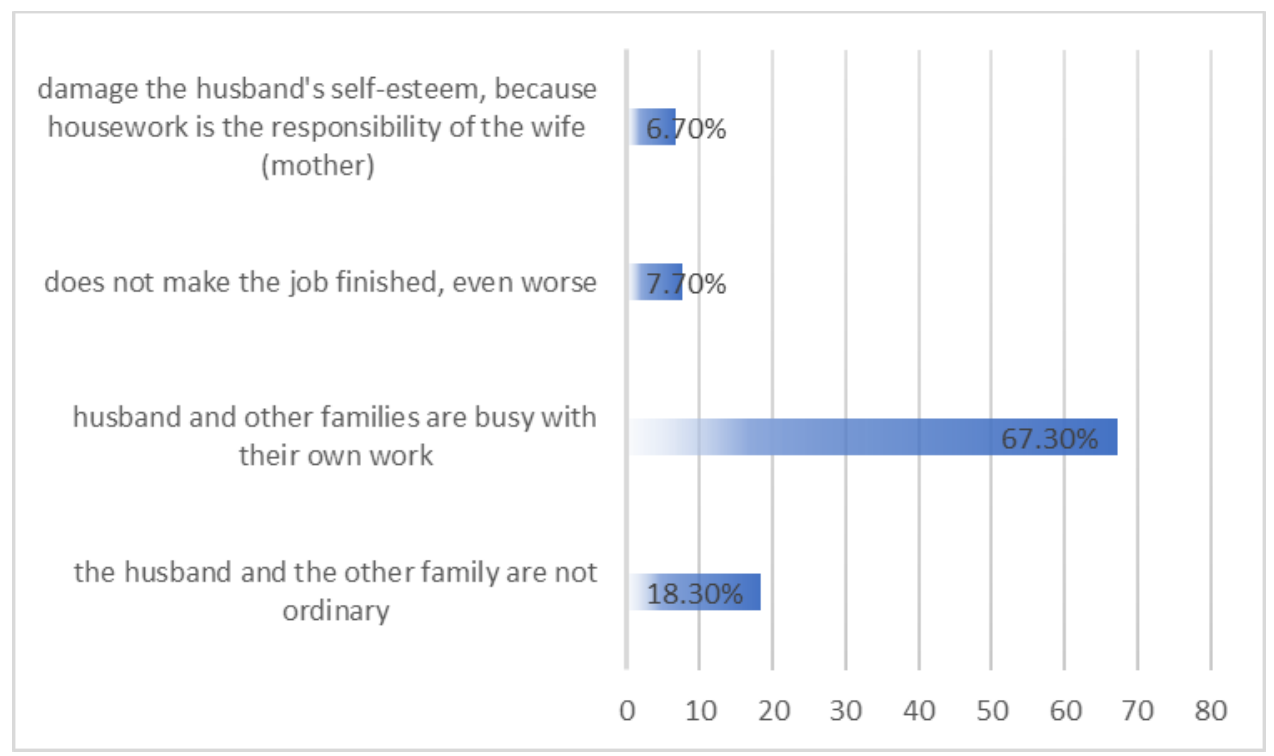

Figure 5. Husband's Response

Box 2. Respondents' responses (husband)

1) Not damage self-esteem, but as a couple must complement each other.
2) Basically helping my wife do housework is an obligation for me, but not for others. One reason is because it is not
usual to do housework.
3) My husband and I disagree that domestic work damages her husband's self-esteem.
4) Not all husbands think so.
5) Each has a task. Help each other certainly in the face of disaster.


6) Because the husband is not used to doing household work.

7) But my husband used to help me with work at home.

8) The statement in (d) is a false statement, if a husband with a willingness to help his wife take care of the household does not will not damage self-esteem, because the household is under the leadership of the husband, meaning that a husband must be able to be an example in a household that he led in all things well and right in order to get God's blessing.

9) In the family, we must help one another and help one another.

10) Habitual factors

11) Domestic work is fully mastered by motivating wives and husbands like Tut Wuri Handayani.

Data image 5 and box two show two information: male (husband) confession in questionnaire and interview: housework done by wife / mother because husband and other family are busy with their respective work (67.30\%), husband and family others are not familiar with domestic work (18.30\%), and other the $(14.40 \%)$. The statement of the respondent (husband) on the questionnaire is almost parallel to the statement in the domestic namely domestic work as a wife / mother's obligation (see statement number 11), household work as part of the division of tasks of husband-wife / men-women (see statement number 5), household chores because husband and children are not used to household chores (see statement number domestic and domestic chores as wife / mother habits.

Still in line with the previous analysis, from the perspective of CDA, the reality of a relationship based on the recognition of a husband (male), this condition is a perpetuation of the domination of men over women in patriarchal society. Domestic works as an obligation, division of labor, unusual boys, and habits are diction that unconsciously perpetuates these conditions. If as an obligation, who is obliged? Cultural processes are deliberately ignored, so they are considered common. If the division of labor, why do women get domestic work? Why is domestic work not distributed as a joint obligation? Unusual boy! Why aren't boys accustomed? And so on, and all of them point to the covert intentions of perpetuating male domination of women in patriarchal society.

Based on data from table 1 to box two data, methodological questions about the comparison of working hours, types of work, to statements of women and men show that domestic work is predominantly carried out by women. The number of jobs and types of work are not merely based on the number increasing, but the segment of the work is increasing. That is, the number of hours can be reduced to one type of work, but the responsibilities of women's work are spread over-all types of work.

\section{Reality of Relationships Based on Women's Working Hours according to CDA The Purpose of Discourse according to Fairclough}

As a discourse, the reality of relations between men and women in patriarchal society households before and during COVID-19, through phrases and diction that were built shows that the discourse was deliberately created by men. In the long run, discourse through said phrases and diction will form knowledge. Words, housework as the destiny of women (wife and daughter), the rightfulness of the wife or mother, habits or traditions, and not normally done by men are historical words inherited by men from men of previous eras. In the long run, the phrase or diction becomes a mental aspect of the cognitive component and transforms into knowledge and understanding. If this is the case, the relationship situation with various discourses that are built becomes a reference for the mindset of both parties. Because it is a reference to the mindset, reasoning delivered is always related to these phrases and diction. Destiny, duty, unusual men, and traditions. Finally, reality as with discourse becomes a truth.

As a truth, this condition is strengthened by the historical aspect of tradition, which occurs in a long period of time. It is increasingly not realized that there is domination or domination of men over women because everything is measured by feelings (sense). Patriarchal societies, both men and women, will assume that they will be wrong if they do not follow this mindset, and will be ostracized in their social relations. In fact, if you fight the mindset is considered to deviate from historical traditions, even against nature as a woman. As a context, this relationship shows the segregation of identity between men and women with attributes in the household. When imagining food and drink, child care, caring for the house, washing and rubbing clothes, the imagined persona is a woman, i.e. wife, mother, or daughter. Two implications that arise in this context, namely, first, if there is a misalignment of the identity in question, women are imaged not well (lazy, not responsible for household affairs, and the like). Second, women will have difficulty adjusting work choices outside of domestic work as identified. For example, a woman obtains public employment opportunities, always faced with the dilemma of public work or domestic responsibilities in the household. In such 
conditions, women are always faced with difficult choices. Domestic reasons are always put forward, and are accepted by both parties as common sense.

\section{Relationship of meaning according to Wodak and Meyer}

The influence of discourse from the context of male and female relations that shapes knowledge and understanding, specifically related to COVID-19 or the other is not realized by both parties in a process of mastery or domination of actors over other groups. Actors in this purpose are men, and victims are women. Clearly, the ideology developed by actors is the perpetuation of dominance. With continued dominance, in the long run, there is an imbalance in the relations of men and women. Men as the beneficiaries, and vice versa women as the losers. In fact, women feel that they are not disadvantaged because their reasoning and cultural aspects have been formed that these are their destinies, obligations and traditions. The question arises, why is that? Two relations of meaning occur. First, the reality of male and female relations in a patriarchal society is identified by different labels or designations. Domestic and household domains are women's labels, and the public domain is men's labels. The relationship between the meaning of the label identification occurs in the long run and is inherited between generations, and is currently considered a norm. Both parties are somewhat difficult to change the mindset because intentionally not created another knowledge other than the meaning that is built up through the relationship. Second, in the long run, the difference in labels is inclusive for women, and exclusive for men. The cognitive reasoning of every patriarchal society will refuse when the label is reversed. Domestic and household labels belong to the male realm, and instead belong to women. Most will rebel, saying they violate the norms and traditions.

As actors with certain ideologies, they will always want to maintain their dominance, because the practice of perpetuating that domination has proven to be beneficial. Therefore, efforts to intensify labels continue to be narrated. This condition will continue to be exacerbated by the support of other reasoning such as religious and cultural reasoning, even though no religion and culture wants a condition of injustice. In practice, cognitive aspects that build knowledge, religious and cultural reasoning work in a number of different patterns. In one context, cognitive reasoning works in defending the ideology of male domination independently, so that women accept it as a norm. In other contexts, when cognitive reasoning has no effect, religious and cultural reasoning are put forward with the same intention, that such relations are natural. Finally, cognitive, religious and cultural reasoning work together in an effort to perpetuate domination so that this relation is accepted as a norm. CDA considers all three as a social problem. When the work patterns of each reason are known as this discussion, the agenda is increasingly clear in solving this problem and reducing the adverse effects on one segment of social relations, namely women.

\section{Sociosemantic according to Van Leeuwen}

Van Leeuwen sees the relation of men and women in patriarchal society as a relation of social actors. The term used is that social relations refers to unbalanced relations between actors and non-actors. Actors usually have an ideology, an act of mastery, and a perpetuation of dominance. Not an actor as a relation where the ideology, mastery, and perpetuation are carried out by the actor. The relation of social actors between men and women in patriarchal society, as the data of this study is understood through two categories of discourse; discourse is exclusive and inclusive. Exclusive discourse with special meaning belongs to men, while inclusive discourse with ordinary meaning belongs to women.

Male privileges in the discourse as above data and information are displayed in public texts, such as the person in charge of the household, decision makers, and served. Included in the meaning of this privilege, men become family representation in public spaces, such as family cards, securities, bank accounts, and other valuable documents. Women's inclusivism is referred to as the attachment of female sex to the type of domestic work, such as in the kitchen, in the yard, in the laundry, to the market, and the like. Including not having access to family representation in public spaces.

The relation of social actors in shaping this discourse, women are considered as objects with nominalization. The term inem is actually a form of nominalization, because the designation is the same as the black, the brown, the red for objects or pets. We rarely hear about Budi, the Rudi, or anything else for men. Another assumption, women as passivation, namely entities that are passive, not dynamic, accept the situation, and even surrender. As evidenced by the data and information of this study, women's recognition of working at home as a destiny, obligation, tradition, and indeed being the treasure of women is a form of passivation, both by themselves and their relationships (men). The next assumption is as generic and specific. Women's work in the household with the type of taking care of eating, drinking, clothing, yard, caring for and supervising children is a common and special work. Prevalent and special is intended to be only the realm of women, and not the realm of men. The relation of social actors with ideology, mastery, as well as various assumptions creates an imbalance in social relations between men and women. Imbalance in CDA's view is a problem. 
CDA in the study found various problems in social relations between men and women in patriarchal societies, especially in the context of COVID-19. The cumulative addition of working hours to all types of domestic work is a cognitive problem, so the condition is understood as normal. The customary according to both parties is historical and inherited. In addition to the positive aspects, the prevalence occurs due to the involvement of religious and cultural reason, so this condition is accepted as a fate and hereditary habit. Methodological questions about causality of working hours, each acknowledging contextual condition during COVID-19 is answered through CDA analysis.

The purpose of CDA's presence is one of the instruments of social change. As an instrument of social change, this study found several aspects involved in the context of relations between men and women, specifically in the context of COVID-19. The involvement of cognitive reasoning, religious reasoning, cultural reasoning power so that mastery, ideological preservation, and domination that benefit men are considered as common. CDA views this reality as a problem. The entrance to unravel the problems is the education process. Strategic education in influencing cognitive in shaping knowledge and understanding, as well as influencing cultural and religious reasoning. CDA does not pretend to fix problems in past generations, but is responsible for fixing problems in future generations.

\section{Conclusions}

As an instrument of social change, the CDA in this study proves that accumulatively, the workload of women during COVID-19 increases. The increase is not calculated based on the increase in each type of work, but overall in each type of work requires the presence of women, as wives, mothers, and daughters. The increase in working hours and recognition of each other in the social realities of patriarchal society shows the involvement of cognitive, religious, and cultural reasoning so that the dominance and perpetuation of the power of social actors are accepted as a norm. This context is a long historical dynamic, and a social problem. As a social problem, the negative effects of this unequal relationship context can be decomposed. CDA in this study offers, the solution to this problem through the educational process, assuming social improvement does not return to history, but moves towards the future.

\section{Acknowledgments}

Thank you to the respondents who were willing to submit information through surveys and interviews despite the difficult conditions of COVID-19. This study was supported by The Smeru Institute Jakarta, the Jakarta Women's Ship, and the West Nusa Tenggara SDGs Research Consortium.

\section{References}

Alisyahbana, A. S. (2017). Menyongsong SDGs: Kesiapan Daerah-Daerah di Indonesia (1st ed.). Bandung: UNPAD Press.

Amer, M. (2017). Critical discourse analysis of war reporting in the international press: the case of the Gaza war of 2008â€"2009. Palgrave Communications, 1-10. https://doi.org/10.1057/s41599-017-0015-2

ASIA AND THE PACIFIC SDG PROGRESS REPORT. (2020).

Basri, M. C. (2020). Indonesian Economy and the COVID-19: Some Policy Responses. Jakarta-Sidney.

Bleck, J., \& Michelitch, K. (2018). Is women's empowerment associated with political knowledge and opinions? Evidence from rural Mali. World Development, 106, 299-323. https://doi.org/10.1016/j.worlddev.2018.01.006

Boldyrev, N. N., \& Dubrovskaya, O. G. (2016). Sociocultural Specificity of Discourse: The Interpretive Approach to Language Use. Procedia - Social and Behavioral Sciences, 236(December 2015), 59-64. https://doi.org/10.1016/j.sbspro.2016.12.019

Bressler, C. E. (2007). Literary Criticism: An Introduction to Theory and Practice (4th ed.). Pearson Eductaion Inc.

Dejardin, A. K. (2011). Conditions of Work and Employment Programme: Advancing Decent Work for Domestic Workers. ILO.

Demirhan, K. (2015). Gender and politics: Patriarchal discourse on social media. 41, 308-310. https://doi.org/10.1016/j.pubrev.2014.11.010

Dildar, Y. (2015). Patriarchal Norms, Religion, and Female Labor Supply : Evidence from Turkey. WORLD DEVELOPMENT, 76(2012), 40-61. https://doi.org/10.1016/j.worlddev.2015.06.010

Dyson, J. (2019). Geoforum Rethinking education as a contradictory resource : Girls' education in the Indian Himalayas. Geoforum, 103(May), 66-74. https://doi.org/10.1016/j.geoforum.2019.03.021

Frias, S. M. (2010). Women 's Studies International Forum Resisting patriarchy within the State : Advocacy 
and family violence in Mexico. Women's Studies International Forum, 33(6), 542-551. https://doi.org/10.1016/j.wsif.2010.09.006

Friedman-sokuler, N., \& Justman, M. (2019). Economics of Education Review Gender , culture and STEM : Counter-intuitive patterns in Arab society ${ }^{2}$. Economics of Education Review, (November), 101947. https://doi.org/10.1016/j.econedurev.2019.101947

Haryatmoko. (2010). Dominasi Penuh Muslihat: Akar Kekerasan dan Diskriminasi (first). Jakarta: Gramedia.

Hiller, V., \& Baudin, T. (2016). Cultural Transmission and the Evolution of Gender Roles * . Mathematical Social Sciences. https://doi.org/10.1016/j.mathsocsci.2016.08.002

Huckin, T., Andrus, J., \& Clary-Lemon, J. (2012). Critical discourse analysis and rhetoric and composition. College Composition and Communication, 64(1), 107-129.

Int, S., \& James, S. M. (1994). Pergamon. 17(6), 563-578.

Jackson, S. (1992). TOWARDS A HISTORICAL SOCIOLOGY OF HOUSEWORK. 15(2), 153-172.

Liu, Y. (2012). Women' s Studies International Forum Decisions to leave home : An examination of rural married women's labour migration in contemporary China. Women's Studies International Forum, 35(5), 305-313. https://doi.org/10.1016/j.wsif.2012.06.001

Moreno, E. (2010). Work - family Conflicts and the Organizational Work Culture as. 17(2). https://doi.org/10.1111/j.1468-0432.2009.00463.x

Nahdi, K., Usuludin, U., Wijaya, H., \& Taufik, M. (2019). Critical discourse analysis on gender relations : women' s images in Sasak song. 7(3), 113-122.

Nash, C. J., \& Catharines, S. (2020). Public Space. 10, 43-47. https://doi.org/10.1016/B978-0-08-1022955.10206-9

Naved, R., Rahman, T., Willan, S., Jewkes, R., \& Gibbs, A. (2018). Social Science \& Medicine Female garment workers' experiences of violence in their homes and workplaces in Bangladesh: A qualitative study. Social Science \& Medicine, 196(November 2017), $150-157$. https://doi.org/10.1016/j.socscimed.2017.11.040

Nayak, S. K. (2017). The Phenomenon of Deconstruction versus the Inherent Desire of Text. International Journal of Trend in Scientific Research and Development, 2(1), 62-68. https://doi.org/10.31142/ijtsrd5863

Orgad, S. (2019). Heading Home: Motherhood, Work, and the Failed Promise of Equality. (April), 1-3. https://doi.org/10.1111/gwao.12399

Rezanova, Z. I., \& Kogut, S. V. (2015). Types of Discourse Markers: Their Ethnocultural Diversity in Scientific Text. Procedia - Social and Behavioral Sciences, 215(June), $266-272$. https://doi.org/10.1016/j.sbspro.2015.11.633

Rincón, G. B., \& Martínez, Y. M. (2020). Work / family life by 2040 : Between a gig economy and traditional roles. Futures, 119(March), 102544. https://doi.org/10.1016/j.futures.2020.102544

Rollefson, I. K. (2017). Purdah, purse and patriarchy: The position of women in the Raika shepherd community in Rajasthan (India). 1-10. https://doi.org/10.1016/j.jaridenv.2017.09.010

Said-allsopp, M., \& Tallontire, A. (2014). Pathways to empowerment ?: dynamics of women 's participation in Global Value Chains. Journal of Cleaner Production, 1-8. https://doi.org/10.1016/j.jclepro.2014.03.089

Salviana, V., \& Soedarwo, D. (2014). Political Ideology Meaning and Patriarchal Ideology of Female Politicians in Indonesia: A Case in Malang. Procedia Environmental Sciences, 20, $486-495$. https://doi.org/10.1016/j.proenv.2014.03.061

Santos, G. G. (2015). Narratives about Work and Family Life among Portuguese Academics. 22(1), 1-16. https://doi.org/10.1111/gwao.12061

Schnurr, S., Zayts, O., Schroeder, A., \& Coyte-hopkins, C. Le. (2019). 'It's not acceptable for the husband to stay at home ': Taking a discourse analytical approach to capture the gendering of work. (July 2018), 1-21. https://doi.org/10.1111/gwao.12408

Seymour, K. (2009). Women, Gendered Work and Gendered Violence: So Much More than a Job. 16(2).

Shahriar, A. Z. M. (2018). Gender di fferences in entrepreneurial propensity : Evidence from matrilineal and patriarchal societies. (April). https://doi.org/10.1016/j.jbusvent.2018.04.005

Skinner, B. (1987). CLASSICAL STUDIES , PATRIARCHY AND FEMINISM: THE VIEW FROM 1986. 10(2), $181-186$.

Swart, E. A., California, S., \& Angeles, L. (2015). Global Violence Against Women. In International Encyclopedia of Social \& Behavioral Sciences (Second Edi, Vol. 10). https://doi.org/10.1016/B978-0-08097086-8.64137-5

UNICEF, B. P. S. (2020). Five Actions for Gender Equality in Teh COVID-19 Responses.

World Food Programme. (2020). Food price update - March 2020. 